\title{
An Exploration of Academic Adjustment for Undergraduate Chinese In- ternational Students
}

\author{
Yin ZHANG \\ No.28 Mingxinzhong road, Wujin, Changzhou, China \\ 347026354@qq.com
}

Keywords: academic adjustment, higher education in American, Chinese students

\begin{abstract}
This study employed a qualitative research method and in-depth interviews research design to examine the academic experience of 25 Chinese undergraduates in the University of Washington. The study investigated five obstacles (language barrier, independence, critical thinking, plagiarism and time management) that influenced Chinese students to perceive their academic wellbeing on campus of American Universities. Recommendations for American professors and Chinese international undergraduates are discussed.
\end{abstract}

\section{Background Information}

According to Kun and David (2010), “Traditional Chinese culture places well-educated scholars in the highest social rank. Academic achievement is also an honor to the family. Dedication to scholarship becomes not only a personal goal but also a cultural goal for Chinese international students.

In the US, about 304,467 (2013/14) university students studied abroad every year and in Spring 2014 about 9,204 Asians with 5,779 Internationals enrolled at the University of Washington (UW). Other countries see similar popularity in study abroad programs. For instance, more than 400,000 Chinese students study abroad every year; 235,000 came to the US; 25\% of UW Undergraduate enrollment for Spring 2013 fell in the category of Asian/Native Hawaiian/ Pacific Islander.

At the institutional level, Chinese students have composed the largest portion of international students in the university where my research is located.Historically, there has long been an assumption that studying abroad inherently, and almost automatically, creates a transformative educational experience. But anecdotal evidence abounds that shows some study abroad experiences may be more valuable educationally than others. Much depends both on how students prepare and engage, encompassing their pre-study abroad orientations, understanding of goals, and active engagement to achieve those goals during the in-country experience. Additionally, much depends on how universities and other partners structure learning experiences for students.

Some find the university a welcoming educational institution and flourish; others may avoid broader engagement with US students and seek to deal primarily with other Chinese students. The result can be a study abroad experience only in the geographical sense, without the broad cultural or intellectual growth that are intended goals of a study-abroad experience.

\section{Research Question}

1. How do Chinese students perceive their academic in the first month of their university experience? How do they learn to negotiate a large public American university's institutional academic?

2. In their academic work at the university, how do Chinese students approach this active learning environment? What is the nature and extent of their interactions with faculty and other university students? What do faculty do (or what could they do) to help these students participate in class and in group assignments? 


\section{Research Method}

\section{Qualitative Methods}

I choose to use qualitative methods for this research instead of quantitative methods because this method cannot only give voice to those who have been marginalized (e.g., Hammersley \& Atkinson, 2010).

\section{In-Depth Interviews}

According to the approved IRB form, I used a digital voice recorder to record conversations and took notes while interviewing. I spoke English to English native speakers and spoke both in English and Mandarin and the Consent form for Chinese students also was in both Mandarin and English.

\section{Participants and Data Collection}

\section{The Research Includes Four Groups of Participants.}

There are 25 Chinese undergraduate students from almost 25 majors, 9 American domestic students, 10 UW faculty and 20 UW staff members taking part in my research throughout the campus.

\section{Question Design}

There are 63 questions for each Chinese undergraduate students concerning study habits, such as language, taking notes, team project, interactions with professors, cheating/plagiarizing, etc. And 26 questions for domestic students, 26 questions for UW faculty, 23-36 questions for different staff and advisors. The data collection period lasted from March 2015 to February 2016.

\section{Data Analysis}

The initial interview transcripts and probing session notes were analyzed as data. The data analysis went hand in hand with the process of data collection, starting from the beginning of data collection. I transcribed interviews and coded audio-recordings, online-related documents, and field observation notes. After data were analyzed, they were all translated into English. Each voice recording file was downloaded to a disk, double checked for clarity, and transcribed.

\section{Results}

The first month seems to be very difficult for most Chinese international students. Although very curious about everything at the beginning, soon they experience homesickness commonly after the excitement wears off. As time passes, most of them tend to settle into a routine when they find that they are starting to be an accepted member here, but there are still a significant part of them who aren't used to studying habits and living in an American environment.

The factors that causes greater pressure on Chinese undergraduates' academic pursuits than those of local students are as followings:

\section{Language Barrier}

The English language remains number one on the list of obstacles. "Culture and education disparities between China and America, together with Chinese students' language deficiencies contribute to their difficulty in having effective communications with American faculty members." (Yan \& Berliner, 2009) In my interviews, most of the undergraduates came from normal high schools in China which tend to have 10-12 hours English classes a week. For a few of the participants who came from foreign language schools, these students usually spend at least 23 hours a week learning English. One third of the participants took the extra English Training courses before they came to the US.

A participant with a History major mentioned: "My English level was just so-so in China, so I took a summer training class before I came to America. I know my IELTS score only shows that 
I'm qualified in the form of a test certificate, but I know I gained this score by concentrating on testing proficiency courses. " For some of the students who come from the foreign language schools, they tend to acclimatized to the English environment much easier, but still have problems in cultural background issues and interpersonal communication.

When asking how some students attempt to solve the issues occurring due to poor English skills, a senior student told me "Reading more after class, creating study groups with other Chinese students and having discussions with other Chinese students seems to work for us. Some of Chinese classmates are brave enough to go and ask professors for explanations and they share it with other students in the study group. We find this method also to be very effective.”

\section{Critical Thinking}

Most of the participants in this interview mentioned that they need to improve their abilities in critical thinking, which is not a very strong point in Chinese education. Chinese education is based on the ancient Confucius system of learning which has strongly influenced our society - it emphasizes that respect must be shown to the teachers always. While in American education, it uses the art of debate and open discussion in order to stimulate critical thought in its students.

"Sometimes I am so afraid of writing because I don't know how to make myself think in a critical way. I am not very used to challenging, criticizing or debating."

One very experienced advisor of Chinese international students stated :"I meet a lot of Chinese students who say that they find it hard to change from simply memorizing to really thinking about what they have learned. That's a huge challenge. Yesterday, a student came to me agonizing with an assignment she was beginning because she had not learned how to write a paper where you are asked to critique other persons written opinion. Critical papers were very hard for her because she has the problem of writing about issues she must look at from her own point of view and possibly disagree with."

\section{Independence}

Most Chinese families dedicate their entire life to the advancement of their children. This is up to and including decisions about what to study and which career path should be taken that assure a acceptable future within Chinese society. Once in school the Chinese student follows the instructions of their teachers. In the daily of life of the Chinese student, life necessities are always handled by the 2 prior generations usually living together. Americans seem to encourage greater independence from a very early age. And the educational system is designed to meet a wide range of academic interests which is very different from China.

"American professors tend to give more space to the students and encourage independence in studying. Chinese teachers are more like baby-sitters, and seem to control too much: like behavior in the class. American professors will rarely initiate help because here you should seek them out if you have problems. Chinese teachers seem to do everything for their students."

"When I come to my professor asking help for my master program, the common response is always ' it is up to you', or 'what do you think or what do you want to do'. I felt overwhelmed and stressed because there were so many choices for me which just made me feel really lost here. In China, my goal is good performance in the class and getting higher scores in the exams, but here I suddenly became aimless without any goal or direction. I don't know what to do."

\section{Plagiarism}

Plagiarism is really a difficult issue for Chinese international students. Attitudes towards cheating and plagiarism appear to be more serious here than in China. Many international students may have trouble understanding the meaning of academic integrity within the U.S. academic culture; and while they may know it in theory, they may not take it seriously or understand it totally. Additionally, the levels and abilities of Chinese students at UW are so different from each other. Some of 
them are very intelligent, while others are not very strong in their academic background. Some of them have just come here because they cannot go to a good university in China or they want to escape from it because we experience very serious competition in our country. And some of them have no choice but to come here because they have very weak learning abilities but the family finds the money so that they come only for the degree. For them, homework becomes a serious burden and they tend to require more help to solve this problem, such as paying the money online or finding someone else to do the homework for them.

"Well, I don't mean to plagiarize because I didn't realize the behavior is considered to be that bad. I'm really nervous when my professor asked me to come to the office and showed me the copied work, I felt so depressed and wanted to dig a hole and hide myself in it (an idiom in China means losing face and escaping far away).”

"I know that American student also have the same problem, but it is a more serious problem with our Chinese students. It's a problem in the undergraduate group here on campus. And most of us don't have this consciousness level, and we don't realize that this is a very serious behavior. When professors discover this problem the methods to resolve it rest with the individual professor. Some of them will give a zero mark, but others may give the student a second chance.”

\section{Time Management}

For most of Chinese students, they are used to finishing the class assignments from teachers within designated hours at a designated location on campus. And teachers are patrolling the areas to assure the work is being done. Their time is totally scheduled and filled with many course hours, homework, and extra tutoring or training classes. Students must simply follow the schedule to be regarded as a good student. When they come to America where education is highly focused on independent choices, they usually don't know what to do and how to manage the time here.

"Time arrangement is really challenge for most of the Chinese students. You know while we were in China, our whole days are so structured from morning to night that teachers tell you what to do and where to do it. But when I came here, I usually have three or four hours class and then, I am free and I have to structure my own study time. That is very hard, you know that we tend to have crazy schedules with almost 15 or 16 hours of class time in China. If nobody tells me what to do next, I will feel very lost and have no sense of achievement."

From the perspective of a UW advisor: "Sometimes, they focus singularly and too much on the major they're studying; for our American students, co-curriculum and experiential learning which are outside your classroom environment is also very important. So it's not just your major, it's more than that. How do you develop yourself as a whole person, and simply thinking that study is job training time is an ineffective method for learning how to learn. And I absolutely think they have a very hard time understanding this concept of balanced personal and academic development.”

\section{Discussion}

How to improve the academic experience of Chinese undergraduates on America campuses? The main problems and complaints from undergraduates are concentrated in choosing majors for the first year. Since the paradigm in China is that every freshman starts his/her university learning experience with a pre-arranged major. Here most of them don't understand at first and always feel lost when choosing majors. More than that, they also need a way to know the resources for collecting the information about services on campus. This is especially important to explain how certain majors can feed into different career choices.

One goal for conducting this study was to support the perception that we can find some ways to help Chinese international students to improve the academic efficacy of Chinese international students on the basis of the research. There are some strategies for American universities to think about:

Providing more training skills on English reading and writing. 
Providing more academic training on critical thinking by giving them understandable materials to discuss.

Encouraging them to give more presentations on the topics that they are more familiar with.

Giving them more time to think about the questions in class and encourage them to express themselves.

For Chinese students, they should learn more about what is involved in studying in the U.S. and try to get familiar as much as possible with the academic requirements of American universities before they come to America. Besides English language study, understanding cultural differences and improving study skills, debating skills, life-skills and relationship skills are also very important. More than that, it's will be very great to have a self-analysis about the feasibility of studying abroad firstly. Studying abroad is not only a happy adventure, but also a challenge for most of the Chinese students

\section{References}

[1]Abouserie, R. (1994). Sources and levels of stress in relation to locus of control and self-esteem in university students. Educational Psychology: An International Journal of Experimental Educational Psychology

[2] Bloor, M. (2012). Chapter 14: Addressing Social Problems through Qualitative Research. In Silverman, D. (ed.) Qualitative Research, 3rd edition (pp.221- 237). Sage.

[3] Clément, R. (1980). Ethnicity, contact and communicative competence in and second language. In H. Giles, W. P. Robinson, \& P. M. Smith (Eds.), Language: Social Psychological Perspectives. Oxford: Pergamon Press.

[4] Glesne, C. (2005). Becoming qualitative researchers: an Introduction. New York: Longman.

[5] Kagitçibasi, C. (2005). Autonomy and relatedness in cultural context: Implications for self and family. Journal of Cross-Cultural Psychology.

[6]Hall, M. E. L., Edwards, K. J., \& Hall, T. W. (2006). The role of spiritual and psychological development in the cross-cultural adjustment of missionaries. Mental Health, Religion \& Culture.

[7]Hammersley, M., \& Atkinson, P. (2010). Ethnography: Principles in practice. London:Routledge.

[8]Mori, S. (2000). Addressing the mental health concerns of international students. Journal of Counseling and Development

[9]Norton, B. (2013). Identity and language learning: Gender, ethnicity and educational change (the second edition). Harlow, UK: Person Education.

[10]Poyrazli, S., Kavanaugh, P. R., Baker, A., \& Al Timimi, N. (2004). Social support and demographic correlates of acculturative stress in internationals students. Journal of College Counseling

[11]Toyokawa, T., \& Toyokawa, N. (2002). Extracurricular activities and the adjustment of Asian international students: A study of Japanese students. International Journal of Intercultural Relations.

[12]Yin, R. K. (2003). Case study research, design and methods, 3rd ed. Newbury Park: Sage Publications. 